\title{
Warring Societies (and Intellectuals)
}

\section{Transforming Cultures eJ ournal, \\ Vol. 1 No 1, March 2006 \\ http:// epress.lib.uts.edu.au/journals/TfC}

\section{Ghassan Hage}

[Non-Refereed]

I'm going to talk about warring societies and the role of academics in them. I'm trying to describe a logic of colonial settler states, which have always conceived themselves to be besieged by uncivilised others and which structure themselves defensively and legitimise these structures in the sense that they have to protect themselves from the uncivilised others surrounding them.

Now to my mind, we in the west, in a variety of ways, have been structuring ourselves as warring societies for a very long time. And this is so well before $9 / 11$. It is important to remind ourselves of this because the question is not whether there is a real threat, like 9/11, or no real threat. This process of structuring ourselves as a warring society starts with the idea that we are surrounded by uncivilised others, that they're out to get us, that refugees from the outside are climbing in; and that also, mothers on the dole are getting us from the inside, that the unemployed are gnawing at our very being. All of these ideas are about the internal and external threats that shape the way we increasingly legitimise society around this notion of how we live and survive such threats. And it is this which has to my mind globalised colonial settler culture.

I think this is especially so when you compare certain cultural forms and cultural and political practices in Israel and the United States. I think there have been a lot of antiSemitic modes of explaining this, saying Jews are controlling American politics and this is why you see Americans acting in this way or that way. But I think it has nothing to do with who's controlling anything! It's just a structural correspondence between two modalities of being generated by two societies structured along similar warring principles. 
In our society even the language of war has become very common: history wars, cultural wars. We seem to be having endless wars. Someone came up with "an Analogy war" the other day. Here we were caught up in "an Analogy war" and no one noticed. But we can't be blamed given how many wars we are surrounded with at the moment. On the positive side, most of us are surviving well, so far, in spite of them.

Now, I'm not simply interested in describing warring society. I'm also interested in describing how academics and particularly intellectuals work and write in these conditions. Of course, this is for me a personal question. Because that's what I am, for better or worse. I am an academic, an intellectual and I'm trying to write. And so what kind of writing can I engage in, in such warring conditions?

The first thing that is important to remember about warring societies is that they emphasise the logic of friends and enemies. I say emphasise because this logic is always present in society. It is the very logic of politics. Politicians don't have the luxury of endlessly questioning where they are standing. Otherwise they'll be totally silly and inefficient as politicians. Politics has the logic of friends and enemies because in politics you have to take positions. At one point or another, you have to stop thinking critically and reflexively and say, "this is where I stand. And it is from this standpoint that I have to act. If you're with me you're my friend if you are not you are my enemy". Intellectuals, on the other hand, can afford to be quite inefficient and indeed, it is part of their ethos. It is ethical for intellectuals to be continuously questioning where they are standing. We can paradoxically say that being practically/politically inefficient, constantly questioning where one has ended up, is part of being an efficient intellectual. And therefore intellectuals are not really position takers, by their very nature. There is a continuous tension between politicians and intellectuals I think. Recently, I said to a political activist friend that I am having second thoughts about the efficiency of the call for the academic boycott of Israel even though it was a good strategy when it was initially introduced. Her response was: "how could you even think that this would be the case?”. I replied that she was a political activist and so she has to stop herself from thinking to maintain her activism. I on the other hand there is nothing that I would stop myself from thinking. I thought that this pretty much captured the difference between us even though we shared a lot in common. 
Now, what's interesting, I think and this what I started by saying, is that this tension between friends/enemies, position taking/acting, intellectual/politician starts collapsing in warring societies, because warring societies cannot afford eternal questioning. You know, we have heard of it in the US when Dick Cheney called academics the weak link in the war on terror. In his view, the weak link means, "you're thinking too much. Enough! We have to fight here!”

Now, very importantly, I think, these two tendencies I've been talking about are simply professionalisation of two tendencies which exist within every citizen. That is, every citizen has one part of them which is about position-taking and one part of them which is about questioning. And warring societies also force that part of the citizen which is questioning to stop existing and for the position-taking, the part that thinks friends/enemies, to take over and become much more dominant in the making of the citizen.

Susan Sontag, I think, put it very nicely when she said that today, in the United States, people are not required to be citizens, they are required to be conscripts. And this logic of conscription is precisely what captures this idea that the citizen has to think in terms of friends or enemy, are you with us or not with us? You're for us or you're against us.

Warring societies, again, like colonial settler societies cannot tolerate the thought of commonness with the other. In fact, they are not very xenophobic in the sense that they are not scared of the difference of the other. They love the other to be different. They love their others to be different and they love their difference. They are not scared of their difference from the others, they're scared of their sameness with the others! That's why in Against Paranoid Nationalism I call this 'homeophobia' (the fear of sameness) not xeno-phobia. I don't want to be put in a position where I'm looking at the other and saying, "she's a human being like me" or "he's a human being like me”, that will disrupt my friends-enemy logic and I don't want to face it. And so culturally different is very good! Again, notice the slogans, “they hate us because they hate us”. Here, as in the discourse of the refugee, there is no sign of envy. The absence of the discourse of envy is very important because usually we can actually insult someone by telling him he is envious of us. But to say to someone, “you're envious," is not a good insult because the envious person is someone who desires what I desire. So if you say, they desire 
what I desire, you're saying they are human beings like us. But in a truly warring logic not even this basic sameness with the enemy should be allowed. They don't hate us because they envy us, they hate us because they hate us. Full stop. Let's not try and find any common ground here.

The sole aim of the "other" is to undermine me, undermine my existence and my sole aim is to find ways of undermining him or her, in order not to let them undermine my own existence. That is the logic of war. This is why the warring society now legitimises slowly and clearly all sorts of practices which are considered within non-warring, normal situations as unethical and illegitimate. Torture, lying, manipulation -- all of these are undemocratic, unethical practices which in normal times we consider don't belong to our society. Suddenly our society starts saying, “That's okay, we can do this”. Recently Georgio Agamben, following Schmidt, argued: “It's a state of exception”. Not only is it a state of exception but it is a wonderful conception, it is a permanent state of exception. A state of exception allows a citizen to legitimise to themselves, and to each other, being undemocratic and unethical, while maintaining the belief in their ethical selves by continuously moving between the two states: in moment A I am a nice democratic ethical person, in moment B I am a warrior who has to kill but soon after I can return to moment A and be myself. Like the soldier, the citizen conscript has to say: "it's true that I am killing the enemy but I am not a killer. Now that I am out of my warring state of exception I can go back to being a good non-killer”. But once this logic creeps in and becomes a permanent state of exception the citizen stops fluctuating between a normal, democratic, ethical state and a warring non-ethical state. Instead the citizen/warrior splits himself or herself into two. Between a contingent citizen and an essential citizen and the contingent citizen is saying basically: "I have to do what I have to do. But even though I have to do what I have to do, my essence is still good. Even though I support torture, I don't really support torture. I have to support torture but really deep down I don’t support it”.

So, the citizen can actually manage to continuously support unethical practices while still maintaining the belief in their ultimate, essential ethical selves. This is again a strong similarity between warring societies and colonial settler societies. Colonial settler societies allow massive torture and repression to happen around them and the colonising people still don’t see it. They say “we do it because we're really superior 
ethical human beings. That's why we have to carry out torture etcetera otherwise we don't do it!”

So, slowly and surely in practice warring societies vacate their democracies. Their democracies become what I'd like to call with a little Lacanian bent, "phallic" democracies. Phallic democracies, you see, are democracies for others as opposed to the democracies for ourselves. They are democracies for show, rather than democracies to live in. What is important is not how you live your democracy but the fact that you have your democracy. This is where the phallic logic creeps in. Once you claim to have a democracy you enter the domain of comparative democracy. My democracy is bigger than your democracy. In fact, not only my democracy can be bigger than your democracy, my democracy can be the only thing there is. You probably have no democracy at all! You see this in the way the conflict is conducted with the Israelis versus the Palestinians. We have democracy, say the Israelis. We have democracy. You don't have democracy. The white South Africans did it to the black South Africans. We do it to all sorts of people. This projective phallic democracy comes hand in hand with the undermining and gutting of lived democracy.

Freedom of speech also becomes vacuous. Any content is emptied out. This Syrian friend I was talking to when I was in Lebanon last year said to me that comparatively Lebanon has a lot more freedom of speech than Syria, in the sense that you can write articles damning the government without going to jail. He said to me, "look, every time I open my mouth in Syria, they put me in jail. Here I say whatever I like and they say to me, we don't give a damn, say whatever you like! Now, I'm not sure whether I prefer freedom of speech or being put in jail, you know, because in Syria someone there is taking seriously what I'm saying whereas here in Lebanon, freedom of speech means they don't give a damn what I'm saying!” What's interesting then about this is that freedom of speech can be undermined in two ways. You can vacate it as a freedom and undervalue freedom, but you can have freedom of speech and undervalue speech and still have freedom of undervalued speech. Speech becomes like breathing: absolutely necessary but pretty meaningless: both indispensable and both with zero political effect. We have the freedom of breathing and we have the freedom of speech. Fantastic! 
So, both colonial settler societies and warring societies undermine speech, subvert speech, subvert the weight of speech by subverting it's impact. There is an ethical content to speech which is vacated also out of that speech. We see it with right wing warriors turning terms which had very high ethical content once upon a time, terms like sexism, racism. Now, you throw sexism or racism at people and they say, Reverse! Reverse sexism. Reverse racism! But the word has no longer any impact in making people stop to think twice about the unethical effect of what they are doing.

How can academics, writers, intellectuals work in conditions such as warring societies? It is a very difficult issue because warring societies by suspending self-criticism for the sake of politics and by encouraging empty vacuous speech, they encourage among intellectuals the production of repetitive and confirmationist discourse. I've witnessed this kind of discourse a lot during the war in Lebanon. It is a mode of writing and speaking in a situation where you know that your audience has given up on trying to learn. In fact they think they know everything there is to know and they listen to you simply to judge whether you know as much as they do. You go and have a political conversation in a café in Ramallah or Tel Aviv and you'll immediately know what I mean. There is no point you saying I am an "expert" or a "researcher" who has discovered all these interesting things that no one knows about. People will openly and contemptuously laugh at you if you say anything other than what fits their understanding of the conflict. And there is no room to shake their firm belief in the absolute correctness of their knowledge. There is a total narcissism and belief in the self as a knowledgeable person and no knowledge from the outside should come to disturb or disrupt this sense of intellectual omnipotence. It is like the wonderful moment when Phillip Ruddock told this guy from a refugee advocacy organisation which the government was financing, "We're paying you to know better". Note the wonderful conception of the production of knowledge that is behind a statement like "we're paying you to know better". It means that Ruddock already knows what is better and what is not better. So, why he is paying the guy in the first place, we don't know. But he pays those people to produce knowledge for him and then he judges whether their knowledge is good which means he already has an absolute knowledge of the knowledge he was seeking! This is what I mean by warriors looking for repetitive and comfirmationist knowledge. They do not respect intellectuals who tells them new things but those who simply repeat and confirm what they already know. They are labelled as "good" and 
even "brilliant” simply according to how well they repeat and confirm one's already absolute knowledge. During the Lebanese civil war many Christian and Muslim intellectuals were celebrated by their respective populations for what was declared "scientific" work which interestingly did not demonstrate anything new. It simply produced a "social scientific" discourse with pseudo research and statistics and historical data which totally proved what people already knew. Such intellectuals were simply adored... we can see more than a shade of this confirmationist discourse in the work of Keith Windshuttle who has brilliantly and scientifically discovered what the conservatives already had a clear gut feeling to be the truth about the history of Australia’s colonisation.

The warriors also claim a monopoly over reality. They claim that reality is on their side. Right-wing warrior discourse in Australia, as much as in colonial settler society, claims a privileged access to reality. Anyone who is not walking along with them suffers from delusions. It is easy to see as one reads Miranda Devine and others. "Get real!” They say, "Stop being in the clouds! Hey, what do you think? Come on, why don't you taste reality as it is." There's a claim that they've got it and everybody else is wafting through the universe. And it's very interesting because this is not a delusion. In fact, actuality is on their side. A very good example of this realism is the phrase, "Well, that's history, okay? It's a bit like Benny Morris also, looking at what has happened in Palestine, saying, “Well, that's it, you know. It happens, that's history!”... And there is an element which is like this in warring societies, where it's like, "Come on, you know, what's past is past, let's face reality as it is instead of moralising about it!”

Here, we need to differentiate along the Aristotelian lines, revived by Agamben, and before that by Deleuze, between actuality and potentiality (or virtuality). Reality is not made up just of reality. Reality is what is actual, but it is also what is possible. What can be, what ought to be, even what is morally possible. And right-wing warring forces try to stop people from thinking about what is possible, what can be, or what ought to be. They appear to be on the side of reality because what is, is on their side and they like people to limit their thoughts to what is. And so the utopian function of intellectuals gets undermined. I think this utopian function of reaching out to what can be, to what ought to be, against what is, is a very important intellectual function today, even if in a warrior society it gets incredibly limited. 